\title{
Hypergonadotrophic Hypogonadism In 2 Siblings With DIDMOAD Syndrome and Its Associations
}

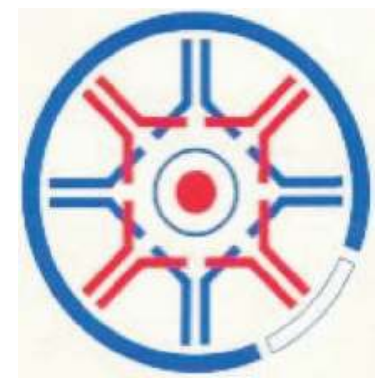

\author{
Amit Kumar Shina S Srikanta, Mary Priya, Srilatha B K, Ashwini K J, Mahesh \\ Manjunath, Harsha A S, Akshaya Hegde, Vibha Rao, Kavitha Vhalve, Vasanthi \\ Nath and the Diabetes Collaborative Study Group.
}

Samatvam Endocrinology Diabetes Center, Diabetes Endocrinology, Bangalore, India

\begin{tabular}{|c|c|c|c|}
\hline $\begin{array}{l}\text { Hypergonadotrophic Hypogonadism with DIDMOAD } \\
\text { Background: Wolfram syndrome } \\
\text { - Rare hereditary / sporadic neurodegenerative } \\
\text { disorder also known as DIDMOAD [WFS1 gene } \\
\text { mutations - encodes an endoplasmic reticulum } \\
\text { membrane protein called “Wolframin” that is } \\
\text { expressed in pancreatic beta cells and neurons.] } \\
\text { - Insulin-dependent diabetes [non-autoimmune] } \\
\text { optic atrophy, central diabetes insipidus, and } \\
\text { sensory neural deafness. }\end{array}$ & $\begin{array}{l}\text { Hypergonadotrophic Hypogonadism with DIDMOAD } \\
\quad \text { Background: Wolfram syndrome } \\
\text { - Neurological and psychiatric manifestations } \\
\text { - Delayed puberty } \\
\text { - Central hypogonadism } \\
\text { - Anterior pituitary hormone dysfunctions - } \\
\text { - Secondary adrenal insufficiency } \\
\text { - Urodynamic abnormalities } \\
\text { - Limited joint motility } \\
\text { - Cardiovascular and gastrointestinal autonomic } \\
\text { neuropathy } \\
\text { - Heart malformations }\end{array}$ & The Effects of Wolfram Syndrome & 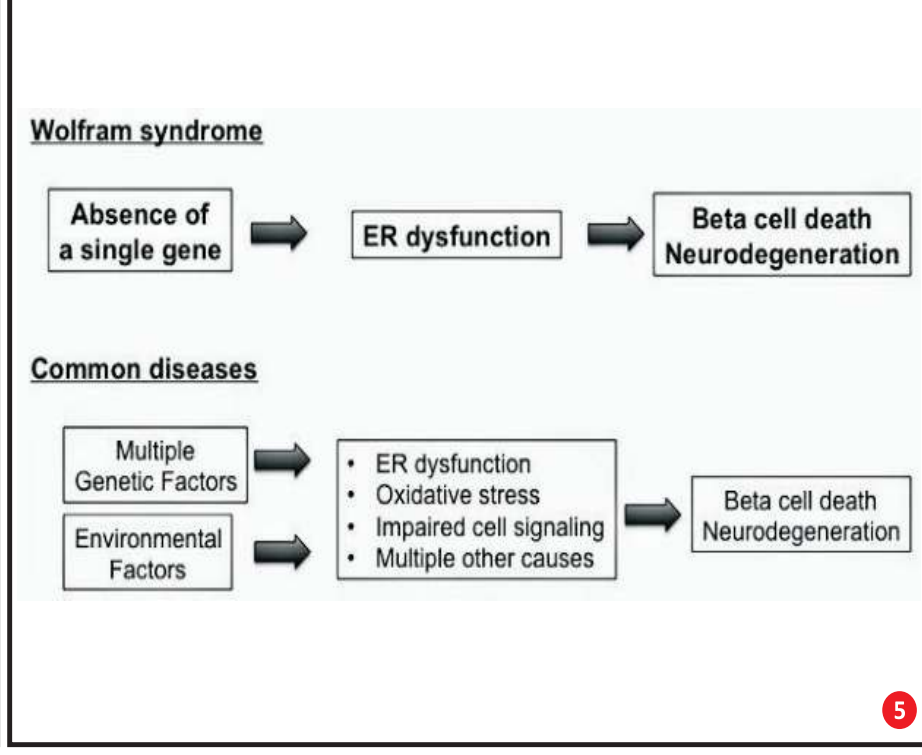 \\
\hline $\begin{array}{l}\text { Hypergonadotrophic Hypogonadism with DIDMOAD } \\
\text { Aim } \\
\text { - To describe hypergonadotrophic } \\
\text { hypogonadism in the rare genetic } \\
\text { autosomal recessive syndrome (Wolfram } \\
\text { Syndrome) in } 2 \text { sisters. }\end{array}$ & $\begin{array}{l}\text { Hypergonadotrophic Hypogonadism With DIDMOAD } \\
\text { Methods: A. Sibling } 1 \\
\text { - Full term normal delivery; } \\
\text { - Age 8: Diabetes insulin dependent } \\
\text { Age 13: Optic Atrophy } \\
\text { - Age 18: Diabetes insipidus } \\
\text { - Age 16: Menarche } \\
\text { - Age 17: Secondary amenorrhea, } \\
\text { - Serum FSH :87.5 } \mathrm{mIU} / \mathrm{ml}, \\
\text { - Testosterone: } 6.9 \mathrm{ng} / \mathrm{dl},\end{array}$ & $\begin{array}{l}\text { Hypergonadotrophic Hypogonadism With DIDMOAD } \\
\text { Methods: A. Sibling } 1 \\
\text { - US Abdomen: } \\
\text { - Small sized uterus, } \\
\text { - Bilateral ovaries hypoplastic / agenesis } \\
\text { - Age 17: Bilateral minimal high frequency } \\
\text { sloping hearing loss } \\
\text { - Right ear PTA 25db, Left ear } 23.3 \mathrm{db}\end{array}$ & $\begin{array}{l}\text { Hypergonadotrophic Hypogonadism With DIDMOAD } \\
\text { Methods: A. Sibling } 1 \\
\text { - Short Stature: } \\
\text { - Height } 146 \mathrm{~cm} ; \quad \% \text { ile: 0\%; Z-score :-2.64; } \\
\text { - Weight } 39.4 \mathrm{kgs} ; \quad \% \text { ile: 0\%; Z-score :-3.13; } \\
\text { - BMl-for-age 18.5; \% ile:13\%; Z-score :-1.11; } \\
\text { - Serum Growth Hormone post clonidine: } \\
\text { - } 6.99 \mathrm{ng} / \mathrm{ml}\end{array}$ \\
\hline $\begin{array}{l}\text { Hypergonadotrophic Hypogonadism With DIDMOAD } \\
\text { Methods: B. Sibling 2 } \\
\text { - Full term normal delivery; } \\
\text { - Age 4: Diabetes insulin dependent; } \\
\text { - Age 15: Optic Atrophy; } \\
\text { - Age 17: Diabetes insipidus; } \\
\text { - Age 15: Menarche; } \\
\text { - Age 16: Secondary amenorrhea, } \\
\text { - Serum FSH } 87.8 \mathrm{mlU} / \mathrm{ml}, \\
\text { - } \text { L } 31.7 \mathrm{mIU} / \mathrm{ml}, \\
\end{array}$ & $\begin{array}{l}\text { Hypergonadotrophic Hypogonadism With DIDMOAD } \\
\text { Methods: B. Sibling } 2 \\
\text { - US Abdomen: } \\
\text { - Small sized uterus, } \\
\text { - Bilateral ovaries hypoplastic / agenesis, } \\
\text { - Left side hydronephrosis; } \\
\text { - Left } \\
\text { - Right normal hearing [Right ear PTA 10db]. }\end{array}$ & 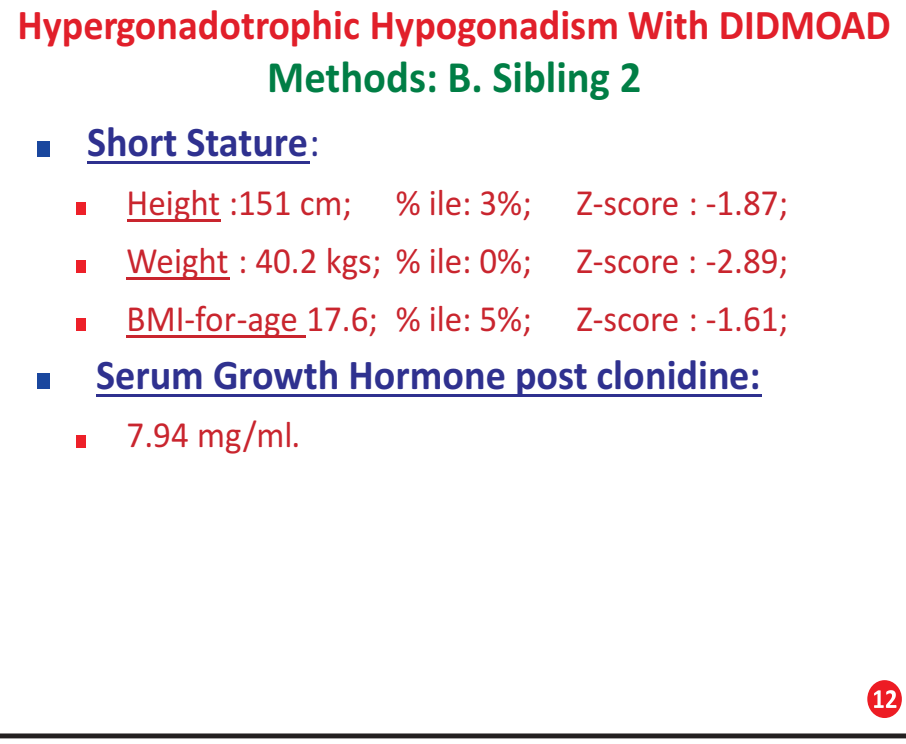 & $\begin{array}{l}\text { Hypergonadotrophic Hypogonadism With DIDMOAD } \\
\text { Conclusion } \\
\text { - Wolframs syndrome being a progressively } \\
\text { devastating multisystem degenerative } \\
\text { disorder can have myriad other } \\
\text { manifestations than the classically described } \\
\text { features. } \\
\text { - Premature death occurs by the fourth decade } \\
\text { of life. } \\
\text { - Short stature is a common feature in WFS. } \\
\text { - Hypogonadism may be hypogonadotropic or } \\
\text { hypergonadotrophic [more reports in males]. }\end{array}$ \\
\hline $\begin{array}{l}\text { Childhood Diabetes Clinics, Residential Diabetes Camps a } \\
\text { Patient Parent Support Groups }\end{array}$ & $\begin{array}{l}\text { Location of mutations leading to Wolfram Syndrome } \\
\text { The genetic mutation that causes this disease takes place on } \\
\text { the WFs1 gene of chromosomen 4p phe, or the upper arm of the } \\
\text { fourth chromosome, and leads to the inability to produce a } \\
\text { protein called Wolframin. }\end{array}$ & $\begin{array}{l}\text { Genotypic classification of patients with Wolfram } \\
\text { syndrome: insights into the natural history of the } \\
\text { disease and correlation with phenotype } \\
\text { - Insights into Wolfram syndrome. (a) Natural history of } \\
\text { WS. The proportion of patients (density) for each } \\
\text { clinical feature at onset age, measured as a } \\
\text { nonparametric probability density distribution, is } \\
\text { plotted. (b) Probability of development of Ws clinical } \\
\text { features by age group. The probability of developing } \\
\text { each of the clinical features over age, calculated using a } \\
\text { life-table analysis, is displayed. } \\
\text { Geneticsin Medicine (2013) 15, 497-506 }\end{array}$ & 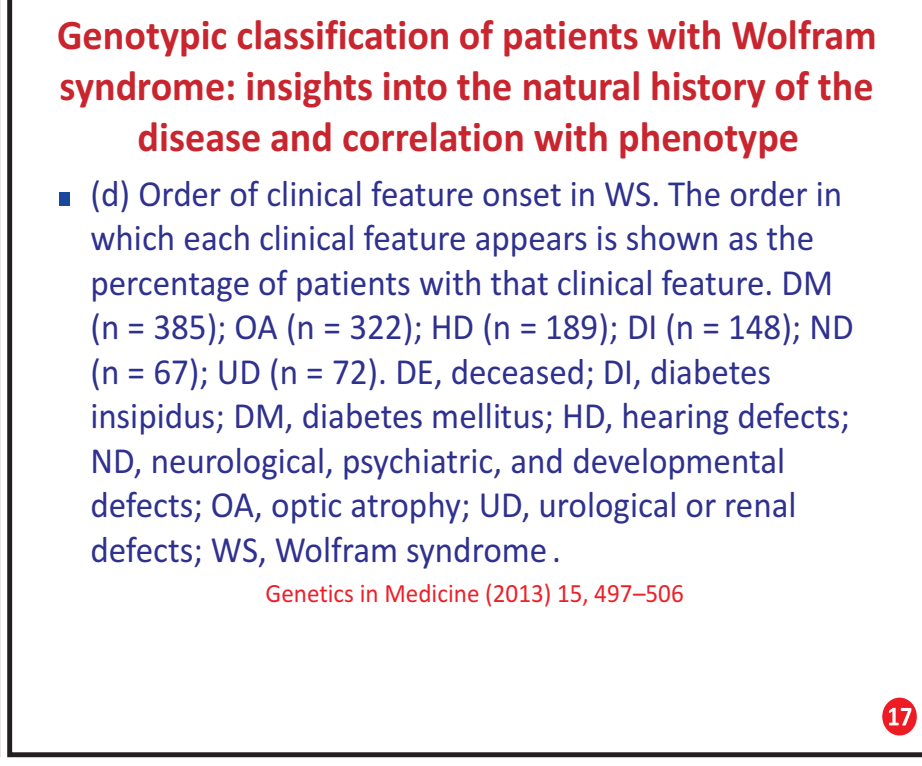 \\
\hline 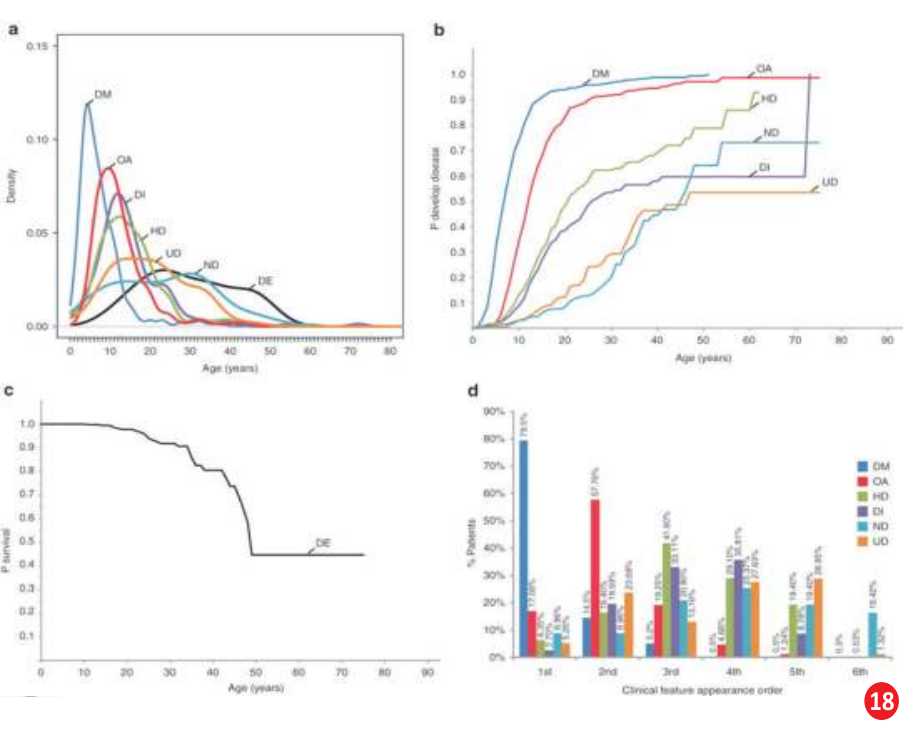 & 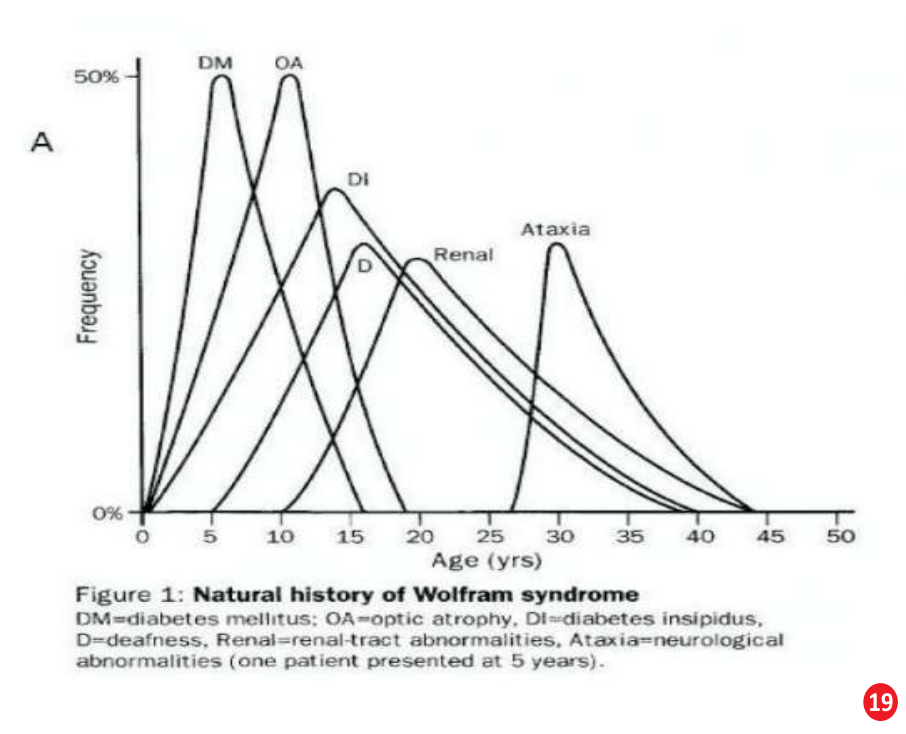 & 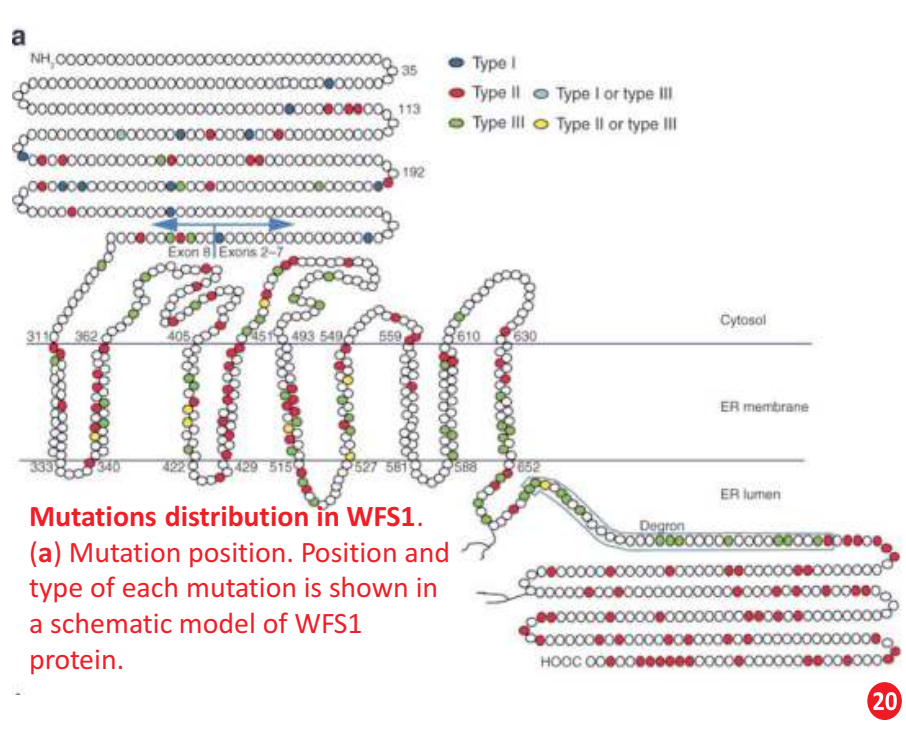 & 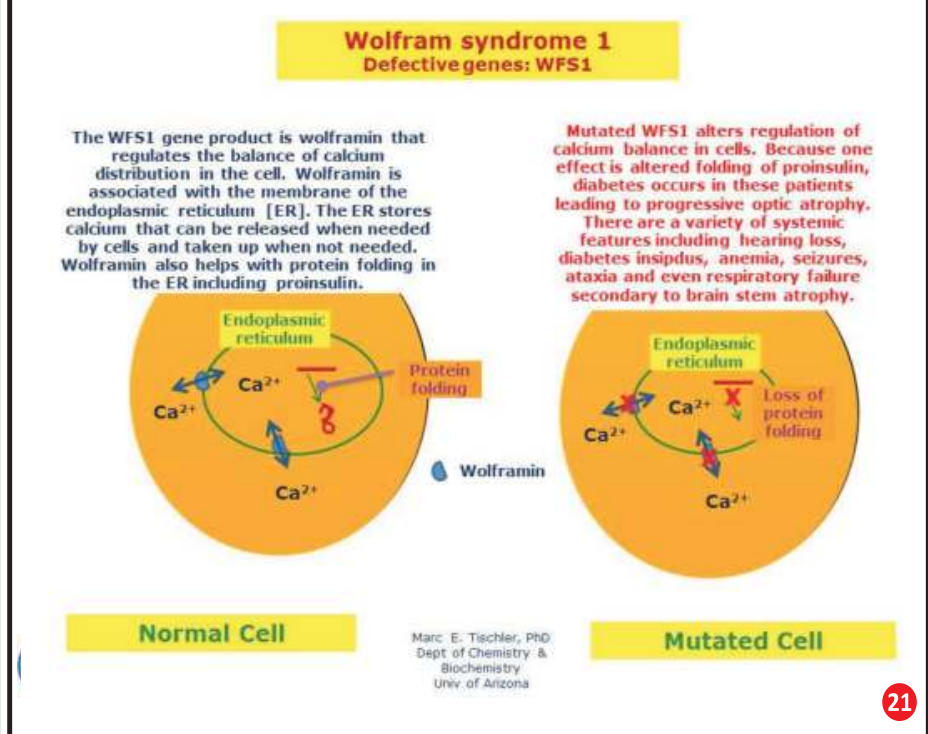 \\
\hline
\end{tabular}

